\title{
$\mathrm{BLDC}$ 고속 센서리스 구동의 ZCP 추정 오차 저감을 위한 Programmable Low Pass Filter 설계
}

\section{A Design of Programmable Low Pass Filter to Reduce the ZCP Estimation Error at High Speed BLDC Sensorless Drive}

\author{
서 은 정**이 강 석**이 우 택 ${ }^{*}$
}

(Eunjeong Seo $\cdot$ Kangseok Lee $\cdot$ Wootaik Lee)

\begin{abstract}
This paper presents a design method of programmable low pass filter(PLPF) which reduce an estimation error of a zero crossing point(ZCP) for a high speed brushless DC(BLDC) motor drive. BLDC motor sensorless drive is possible by estimation of ZCP. The ZCP estimated by detecting a change of back-EMF polarity has the estimation error because noises exist on the measured back-EMF. Therefore a calculated commutation timing using the ZCP is inaccurate. And the inexact commutation timing leads to ripples of 3-phase current and degradation of drive performance. This paper proposes the design method of the PLPF to overcome these problems. First, a speed calculated a inaccurate period of the ZCP is analyzed in the frequency domain. Then, the PLPF that has varying cut-off frequency according to change of the speed is designed on the frequency analysis result. The proposed method is verified by the experiment.
\end{abstract}

Key Words : Brushless DC motor, Sensorless, Zero crossing point, Programmable low pass filter, Measurement nois of terminal voltage, Estimation error

\section{1. 서 론}

Brushless $\mathrm{DC}(\mathrm{BLDC})$ 전동기는 $\mathrm{DC}$ 전동기의 기계적 접 촉 구조인 정류자와 브러시를 제거하여, 전자적인 정류를 이 용하여 신뢰성을 향상 시킨 전동기이다. 이러한 $\mathrm{BLDC}$ 전동 기는 간단한 구조, 우수한 내구 수명, 고효율, 고토크 등의 장점으로 인해 다양한 산업분야에 많이 이용되고 있다[1-4] 하지만 전자적인 정류를 위해서는 영구자석의 회전자의 위 치 정보를 알아야 하기 때문에 홀센서, 레졸버 및 엔코더와 같은 위치 센서를 필요로 하는데, 위치 센서의 장착으로 인 해 전동기 시스템의 가격 상승, 부피 증가, 사용 환경의 제 약 등 많은 문제들이 야기된다. 이러한 문제를 해결하기 위 해서 위치 센서를 사용하지 않고 회전자의 위치를 간접 검 출하여 $\mathrm{BLDC}$ 전동기를 구동하는 센서리스 기법에 관한 연 구가 활발히 진행되고 있다[5-7]. 특히 센서리스 기법 중 역 기전력이 ' 0 '이 되는 시점( $\mathrm{ZCP}$, Zero Crossing Point)을 검출 하고, 이를 이용하여 전류의 전환 시점을 계산하여 구동하는 방법이 많이 사용되고 있다.8) 역기전력은 스위칭하지 않는 상의 단자 전압(terminal voltage)을 PWM 주기와 동기화하 여 샘플링함으로써 얻을 수 있으며, 역기전력의 극성이 변화 한 시점을 $\mathrm{ZCP}$ 로 판단내린다.

† Corresponding Author: Dept. of Control \& Instrumentation Engineering, Changwon National Univ., Korea

E-mail : wootaik@changwon.ac.kr

* Department of Control \& Instrumentation Engineering, Graduate School, Changwon National Univ., Korea

Received : August 12, 2013; Accepted : December 17, 2013
하지만 검출된 $\mathrm{ZCP}$ 에는 추정 오차가 존재하기 때문에 정 확한 전류의 전환 시점을 계산 할 수 없다. 정확하지 않은 전류의 전환 시점으로 인해 전류 리플이 증가하는데, $\mathrm{BLDC}$ 전동기 구동에서 전류 리플은 진동, 소음의 원인이 되는 토 크 리플을 증가시키는 가장 큰 요인이므로 이는 구동 성능 의 저하를 야기 시킨다[9]. 이러한 추정 오차의 원인으로는 단자 전압의 샘플링 주기의 제한과 단자 전압의 측정 노이 즈의 두 가지로 나눌 수 있다[10]. 단자 전압의 샘플링 주기 의 제한으로 인한 추정 오차는 한 회전당 단자 전압의 샘플 링 수가 적은 고속에서 오차가 심화되는 특징이 있으며, $\mathrm{ZCP}$ 간의 주기에 저역 통과 필터를 적용함으로써 이러한 추 정 오차를 저감시키는 방법이 연구되었다[11].

$\mathrm{ZCP}$ 추정 오차의 원인인 단자 전압의 측정 노이즈를 저 감시키기 위해서 단자 전압을 직접 필터링하는 방법을 생각 해 볼수 있는데, 전환 구간으로 인해 샘플링되는 단자 전압 이 불연속적이서 필터를 적용하기가 어렵고, 필터를 적용한 다 하더라도 고속에서는 단자 전압의 샘플 개수가 적기 때 문에 그 효과가 제한적이다. 따라서 $\mathrm{ZCP}$ 주기로 계산되는 속도를 필터링함으로써 간접적으로 $\mathrm{ZCP}$ 의 추정 오차를 저 감시키는 방법을 사용해야한다. 하지만 단자 전압의 측정 노이즈로 인한 추정 오차는 구동 속도에 따라서 그 주파수 특성이 변하기 때문에 필터의 차단 주파수를 작게 설정하면 추정 오차 저감은 효과적이지만 속도 응답이 느려지고, 반대 로 차단 주파수를 크게 설정하면 속도 응답은 빨라지지만 추정 오차 저감 효과가 적다.

본 논문에서는 $\mathrm{ZCP}$ 주기로 계산되는 속도의 주파수 분석 을 바탕으로 구동 속도에 따라 필터의 차단 주파수가 가변 되는 프로그래머블 저역 통과 필터(Programmable Low 
Pass Filter)를 설계하였다. 설계한 필터를 적용함으로써 넓 은 구동 영역에서 단자 전압의 측정 노이즈로 인한 $\mathrm{ZCP}$ 추 정 오차를 저감시킬 수 있고, 이는 토크 리플을 감소시켜 $\mathrm{BLDC}$ 전동기 구동에서 발생하는 진동, 소음을 줄일 수 있 다. 실험을 통하여 제시된 방법을 통해 $\mathrm{ZCP}$ 추정 오차가 저 감됨을 전류 리플률을 비교함으로써 검증하였다.

\section{2. 역기전력의 ZCP를 이용한 센서리스 구동}

\subsection{BLDC 전동기 센서리스 구동원리}

$\mathrm{BLDC}$ 전동기는 일반적으로 사다리꼴의 역기전력을 갖기 때문에 $120^{\circ}$ 도통 구간을 갖는 구형파 전류로 구동한다. 이 때 $60^{\circ}$ 씩 여섯 개의 섹터(sector)로 나눌 수 있으며, 섹터에 따라 도통 순서를 바꿔 권선의 전류를 바꾸어 주면 일정한 방향으로 토크가 발생하여 회전하게 된다. 그림 1 은 $\mathrm{BLDC}$ 전동기 구동 시 3 상 단자 전압을 측정한 결과이다.

$\mathrm{BLDC}$ 전동기는 2 상 여자 방식 구동이므로 그림 1 과 같 이 스위칭하지 않는 구간(switching-off region)이 존재한다. 이러한 구간에서 단자 전압을 측정하여 역기전력의 $\mathrm{ZCP}$ 를 검출 할 수 있다. $\mathrm{ZCP}$ 로부터 $30^{\circ}$ 가 지난 시점이 상전류를 전환하는 시점이므로 이 시점에서 전류의 도통 순서를 바꿔 줌으로써 $\mathrm{BLDC}$ 전동기의 센서리스 구동이 가능해진다.

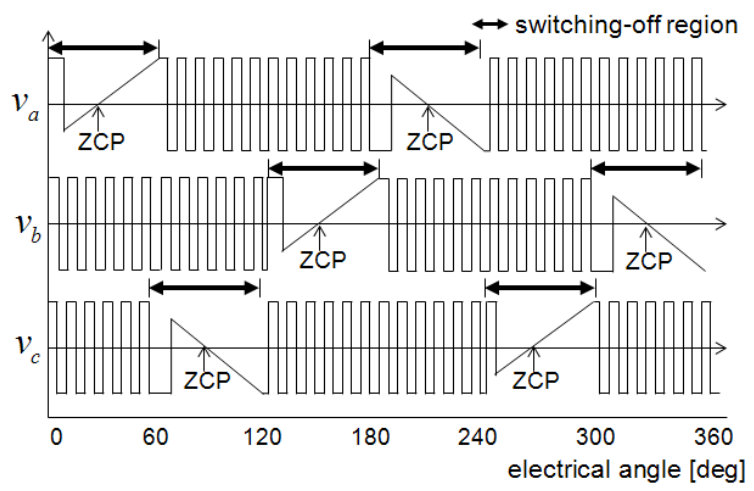

그림 $1 \mathrm{BLDC}$ 전동기의 3상 단자 전압 파형

Fig. 13 -phase terminal voltage of BLDC motor

\section{$2.2 \mathrm{ZCP}$ 검출과 전류의 전환 시점 계산}

$\mathrm{BLDC}$ 전동기의 역기전력은 스위칭하지 않는 상의 단자 전압을 측정함으로써 얻을 수 있는데, 전동기의 중성점과 인 버터 접지 간의 전위차로 인해 단자 전압은 항상 직류 링크 전압(DC link voltage)의 $1 / 2$ 배만큼 큰 값을 갖는다. 본 논문 에서는 단자 전압을 샘플링할 때 이를 고려하고, 샘플링된 단 자 전압과 역기전력의 크기 차이가 없는 것으로 간주하였다.

그림 2 는 $\mathrm{BLDC}$ 전동기의 구동 시 측정되는 단자전압과 실제 역기전력을 나타낸 그림이다. 전동기의 유한한 인덕턴 스로 인해서 전환 직후 스위칭하지 않는 상에 전류가 흐른 다. 이러한 전류로 인하여 전환 구간(commutation period)이 존재하며, 이 구간에서는 역기전력을 측정 할 수가 없다.

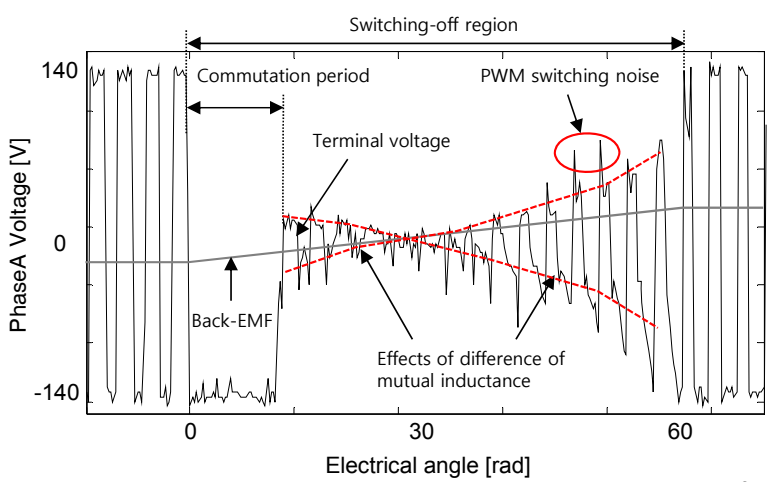

그림 $2 \mathrm{BLDC}$ 전동기의 역기전력과 단자 전압

Fig. 2 Back-EMF and terminal voltage of BLDC motor

전환 구간 후에는 전동기의 상호 인덕턴스 불균형에 의한 영향으로 인해 그림 2에 보이는바와 같이 역기전력에 $\mathrm{PWM}$ 파형이 중첩되어 나타며, $\mathrm{PWM}$ 스위칭 시 노이즈가 발생한 다. 따라서 역기전력을 PWM 스위칭 주파수에 동기화하여, $\mathrm{PWM}$ 중간 지점에서 샘플링하는 것이 바람직하다. 이렇게 샘플링된 단자 전압의 극성 변화로부터 Zero Cross Point (ZCP)를 추정하게 된다.

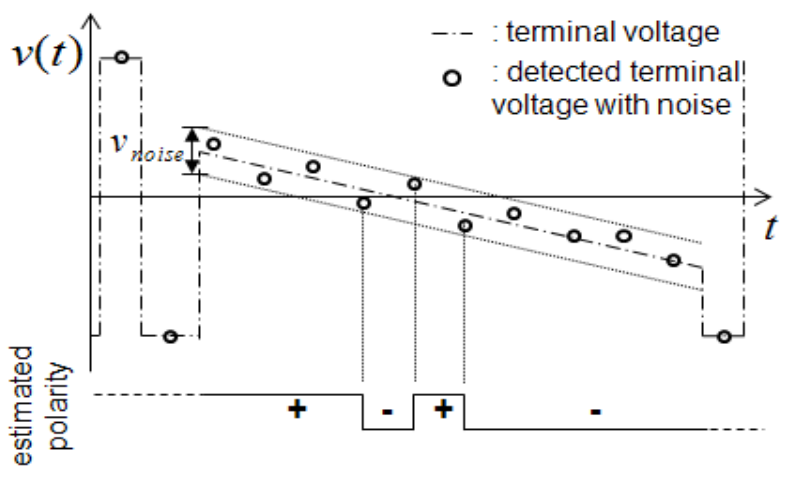

그림 3 역기전력의 노이즈로 인한 영향

Fig. 3 The effects of back-EMF noise

하지만 화이트 노이즈와 앞서 언급한 스위칭 노이즈, 상 호 인덕턴스 불균형에 의한 영향, 그리고 정확히 PWM 중 간 지점에서 샘플링이 되지 않는 경우 등에 의하여 샘플링 된 단자 전압은 실제 역기전력에 $V_{n o i s e}$ 의 크기를 갖는 측정 노이즈가 더해진 형태로 나타나게 된다. 이러한 측정 노이 즈로 인해 저속에서는 그림 3 과 같이 $0[\mathrm{~V}]$ 부근에서 극성이 여러 번 변화하는 채터링(Chattering) 현상이 나타는데, ZCP 추정 시 히스테리시스 밴드(hysteresis band)를 적용함으로 써 이러한 채터링 현상을 방지할 수 있다. 그림 4에 역기전 력의 극성이 $(+)$ 에서 $(-)$ 로 변화할 경우 히스테리시스 밴드 를 적용하여 $\mathrm{ZCP}$ 를 추정하는 방법을 나타내었다. $V(t)<V_{L T}$ 를 만족하는 시점을 $\mathrm{ZCP}$ 로 추정하며, 추정 시점을 $\widehat{t_{z c}}$ 라 한다. 이때 $V(t)$ 는 측정되는 단자전압이고 $V_{U T}$ 와 $V_{L T}$ 는 히스테리시스의 문턱(Threshold) 전압이다.

역기전력 극성이 $(-)$ 에서 $(+)$ 로 변화하는 경우에는 $V(t)>$ 
$V_{U T}$ 를 만족하는 시점을 $\mathrm{ZCP}$ 로 추정한다. 이렇게 추정된 현재 섹터의 $\mathrm{ZCP}$ 시점 $\hat{t_{z c}}$ 와 이전 섹터의 $\mathrm{ZCP}$ 시점으로부 터 $\mathrm{ZCP}$ 간의 주기 $\widehat{T}_{z c}$ 를 구하여, 전류의 전환 시점 $\widehat{t_{c m t}}$ 을 식(1)과 같이 계산한다.

$$
\widehat{t_{c m t}}=\widehat{t_{z c}}+\frac{\widehat{T_{z c}}}{2}
$$

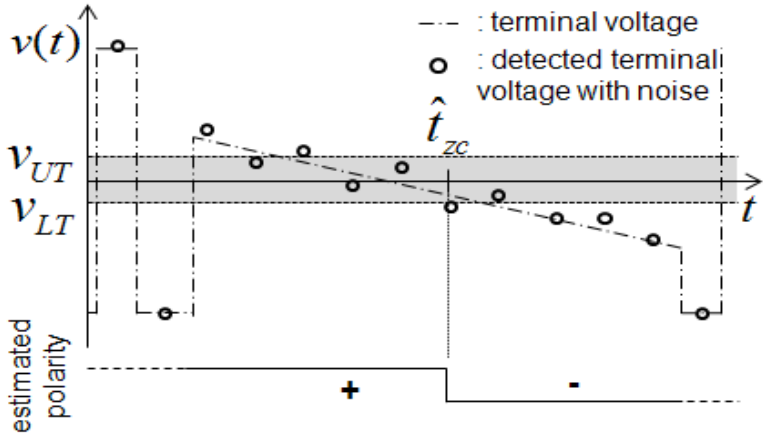

그림 4 히스테리시스가 적용된 ZCP 추정

Fig. 4 ZCP detection with hysteresis

\section{$2.3 \mathrm{ZCP}$ 추정 오차 저감을 위한 $\mathrm{BLDC}$ 전동기 센서리스 구동}

이러한 추정오차로 인해 정확한 전류의 전환 시점을 계 산할 수 없다. 따라서 실제 전환이 이루어져야 하는 시점보 다 앞선 시점이나 혹은 느린 시점에서 전환이 이루어져 전 류의 리플이 증가하고 구동 성능이 저하된다. 일반적으로 노이즈의 영향을 저감하기 위해서는 노이즈가 존재하는 신 호를 직접 필터링하지만, 전환 구간으로 인해 샘플링 된 역 기전력이 불연속적이며 고속에서는 $\mathrm{ZCP}$ 를 검출하는데 사용 되는 역기전력 샘플이 적기 때문에 필터를 적용하더라도 필 터링 효과가 제한적이다.

$\mathrm{BLDC}$ 전동기의 센서리스 구동 시 $\mathrm{ZCP}$ 간의 주기를 이용 하여 속도를 계산하기 때문에 $\mathrm{ZCP}$ 추정 오차는 곧 속도 오 차로 나타난다. 따라서 필터링된 속도로부터 $\mathrm{ZCP}$ 간의 주기 를 계산하고, 이를 이용하여 전류의 전환 시점을 계산함으로 써 $\mathrm{ZCP}$ 의 추정 오차의 영향을 저감할 수 있다.

3장에서 속도의 필터를 설계하기 위하여 $\mathrm{BLDC}$ 전동기 구동 시 속도를 주파수 분석하고, 이를 바탕으로 추정 오차 저감을 위한 프로그래머블 저역 통과 필터 (Programmable Low Pass Filter) 를 설계하였다.

\section{3. 프로그래머블 저역 통과 필터 설계}

\subsection{ZCP 추정 오차 분석}

2장에서 $\mathrm{ZCP}$ 를 검출하고, 검출된 $\mathrm{ZCP}$ 로부터 전류의 전 환 시점을 계산한하는 방법을 설명했다. 하지만 앞서 설명 한 단자 전압의 노이즈와 히스테리시스 밴드를 적용함으로 써 실제 $\mathrm{ZCP}$ 와 검출된 $\mathrm{ZCP}$ 간에는 추정 오차가 발생한다. 그림 5 에 이러한 추정 오차를 나타내었다. $t_{z c}$ 는 실제 $\mathrm{ZCP}$
이며, $T_{z c}$ 는 실제 $\mathrm{ZCP}$ 간의 주기로 전기각으로 $60^{\circ}$ 이다. $t_{c m t}$ 은 $t_{z c}$ 로부터 $30^{\circ}$ 가 지난 시점인 전류의 전환 시점을 나타낸 다. $\widehat{t_{z c}}, \widehat{T_{z c}}, \widehat{t_{c m t}}$ 은 앞에서 정의한 $\mathrm{ZCP}$ 검출을 통해 계산되 는 값이며, $T_{e r r}$ 는 $t_{z c}$ 에 대한 $\widehat{t_{z c}}$ 의 추정 오차를 나타낸다.

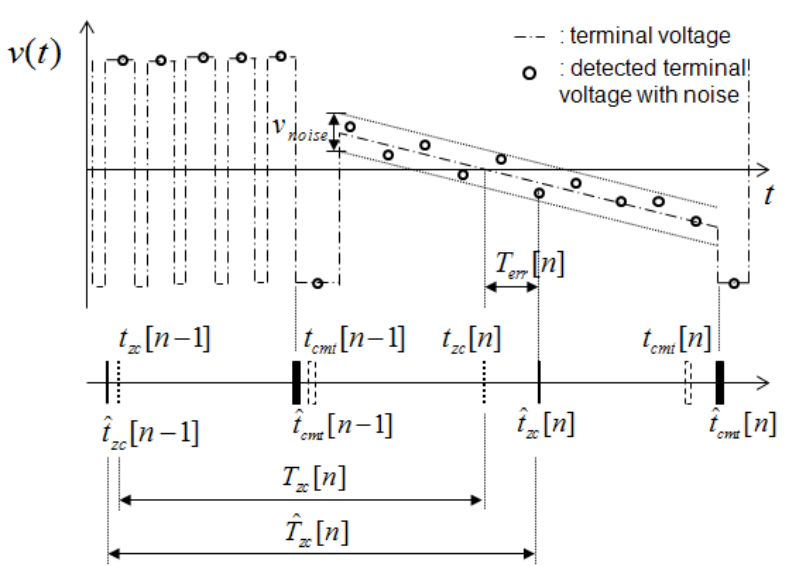

그림 $5 \mathrm{ZCP}$ 의 추정 오차

Fig. 5 Estimation error of ZCP

식(2)와 같이 추정된 $\mathrm{ZCP}$ 간의 주기 $\widehat{T}_{z c}$ 에는 추정 오차 $T_{\text {err }}$ 가 존재한다.

$$
\begin{aligned}
\widehat{T_{z c}}[n] & =\widehat{t_{z c}}[n]-\widehat{t_{z c}}[n-1] \\
& =\left(t_{z c}[n]+T_{e r r}[n]\right)-\left(t_{z c}[n-1]+T_{e r r}[n-1]\right) \\
& =T_{z c}[n]+T_{e r r}[n]-T_{e r r}[n-1]
\end{aligned}
$$

따라서 $\mathrm{ZCP}$ 간의 주기를 필터링하여 이러한 추정 오차의 영항을 저감하고자 한다. 하지만 필터링된 $\mathrm{ZCP}$ 간의 주기와 실제 $\mathrm{ZCP}$ 간의 주기가 같다고 가정하더라도, 식 (3)과 같이 여전히 $\mathrm{ZCP}$ 에 추정 오차가 존재하기 때문에 정확한 전류의 전환 시점을 계산하기 어렵다. 따라서 전류의 전환 시점을 계산 할 때, 식 (4)와 같이 필터링된 $\mathrm{ZCP}$ 간의 주기를 이용 하여 추정 오차가 저감된 이전의 전류의 전환 시점으로부터 다음 전류의 전환 시점을 계산함으로써 추정 오차가 저감된 전류의 전환 시점 계산이 가능하다. 이 때 $\widetilde{T}_{z c}$ 는 필터링된 $\mathrm{ZCP}$ 간의 주기를 나타낸다.

$$
\begin{aligned}
& \widehat{t_{c m t}}[n]=\widehat{t_{z c}}[n]+\frac{1}{2} \widetilde{T}_{z c}[n] \\
& \approx t_{z c}[n]+T_{e r r}[n]+\frac{1}{2} T_{z c}[n] \\
& \widehat{t_{c m t}}[n]=\widehat{t_{c m t}}[n-1]+\widetilde{T}_{z c}[n]
\end{aligned}
$$

$\widetilde{T}_{z c}$ 를 구하기 위해서 속도의 주파수 분석을 통해 $\mathrm{ZCP}$ 추 정 오차를 분석하고자 한다. $\mathrm{BLDC}$ 전동기 구동 시 $\mathrm{ZCP}$ 의 주기는 곧 속도이기 때문이다. $\mathrm{ZCP}$ 의 주기와 기계 각속도의 관계는 식(5)와 같으며, $\widehat{w_{m}}$ 은 $\mathrm{ZCP}$ 간의 주기로 계산되는 전 동기의 기계 각속도를, $P$ 는 전동기의 극수를 나타낸다. 


$$
\widehat{w_{m}}=\frac{60}{\widehat{T}_{z c}(P / 2)} \frac{1}{6}
$$

센서리스로 정속 구동 시 속도의 변화를 그림 6 에 나타내 었다. 점선이 이상적인 속도이며 실선은 $\mathrm{ZCP}$ 의 주기로부터 계산되는 속도를 나타낸다. $\mathrm{ZCP}$ 가 전기각 $60^{\circ}$ 마다 검출이 되므로 속도 또한 $60^{\circ}$ 마다 계산되게 된다. 점선과 같이 속도 가 $1500[\mathrm{rpm}]$ 으로 일정할 것으로 기대하지만, $\mathrm{ZCP}$ 추정 오 차로 인해 속도가 실선과 같이 변화한다.

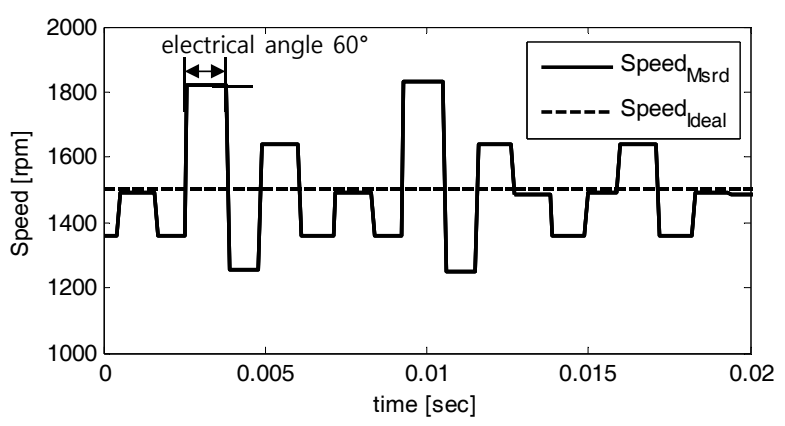

그림 6 1500[rpm] 구동 시 속도 변화

Fig. 6 Speed variation at 1500[rpm]

이러한 속도를 FFT를 이용하여 주파수 영역에서 분석하 였다. 이 때 속도의 샘플링 주파수는 $10 \mathrm{k}[\mathrm{Hz}]$ 이며, 전동기의 구동 속도가 기계각으로 $500,1500,2500[\mathrm{rpm}]$ 일 때의 결과 를 차례대로 그림 7에 나타내었다. $500[\mathrm{rpm}]$ 으로 구동한 경 우, 속도가 일정하다면 $0[\mathrm{~Hz}]$ 에서 $500[\mathrm{rpm}]$ 의 크기를 가지는 성분만 존재해야한다. 하지만 $\mathrm{ZCP}$ 추정 오차로 인해 $0[\mathrm{~Hz}]$ 이외의 주파수에서 속도 변화에 의한 노이즈 성분이 존재하 며, 특히 $50,100,150[\mathrm{~Hz}]$ 에서 이러한 노이즈 성분의 크기가 크게 나타남을 확인 할 수 있다. 식(6)을 이용하여 전동기의 구동 속도를 전기각의 구동 주파수로 $[\mathrm{Hz}]$ 로 변환할 수 있는 데, 실험에 사용한 전동기의 극수가 12 극이므로 $500[\mathrm{rpm}]$ 일 때의 전기각 구동 주파수는 $50[\mathrm{~Hz}]$ 가 된다. 따라서 $\mathrm{ZCP}$ 추 정 오차로 인한 속도의 노이즈 성분이 전기각 구동 주파수 를 기본 주파수(Fundamental frequency)로 하는 1, 2, 3 고 조파에서 나타남을 알 수 있다.

$$
f_{w_{e}}=\frac{w_{m}(P / 2)}{60}
$$

$1500[\mathrm{rpm}]$ 에서도 전기각 구동 주파수 $150[\mathrm{~Hz}]$ 의 $1,2,3$ 고조파인 $150,300,450[\mathrm{~Hz}]$ 에서 상대적으로 큰 속도 노이즈 성분이 존재하였고, $2500[\mathrm{rpm}]$ 에서도 동일한 양상을 확인하 였다.

\section{2 프로그래머블 저역 통과 필터 설계}

3.1절에서 $\mathrm{ZCP}$ 추정 오차로 인해 나타나는 속도의 노이 즈 성분들이 전기각 구동 주파수의 고조파로서, 구동 속도에 따라서 그 주파수가 가변되는 것을 확인하였다. 이러한 $\mathrm{ZCP}$ 추정 오차의 영향의 저감을 위하여, 일반적인 저역 통과 필
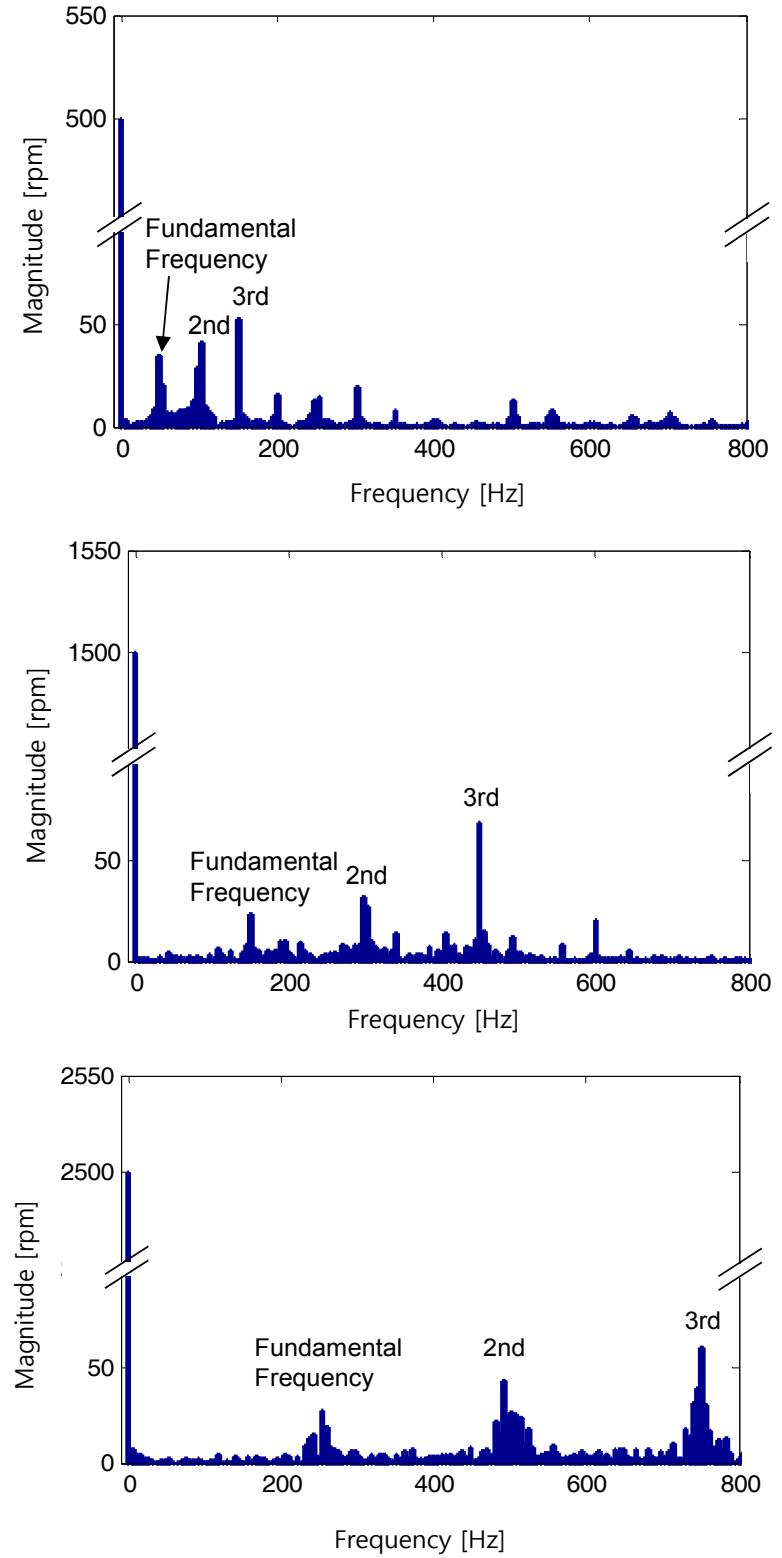

그림 7 속도의 FFT 분석

(500[rpm](위), 1500[rpm](중간), 2500[rpm](아래))

Fig. 7 FFT Analysis Result

(500[rpm](Top), 1500[rpm](Middle), 2500[rpm](Bottom))

터를 사용하여 차단 주파수(cut-off frequency)를 50[Hz]보 다 작게 고정하면 전 속도 영역에서 속도의 오차의 영향을 제거할 수는 있지만 속도의 응답이 느려지는 단점이 있다. 반대의 경우로, 속도 응답을 빠르게 하기 위해서 고속에서의 $\mathrm{FFT}$ 결과를 기준으로 차단 주파수를 설정하게 되면 저속에 서의 $\mathrm{ZCP}$ 추정 오차의 영향을 저감하는데 한계가 있다. 따 라서 속도에 따라 차단 주파수를 가변 할 수 있는 프로그래 머블 저역 통과 필터(Programmable Low Pass Filter)를 이 용함으로써 전 속도 영역에서 $\mathrm{ZCP}$ 추정 오차의 영향을 제 거하고, 고속에서는 빠른 속도 응답을 얻을 수 있도록 하고 자 한다. 필터의 기본 형태는 1 차 저역 통과 필터로 설정하 여 식(7)와 같은 전달 함수를 갖는다. 이 때, $w_{c}$ 는 차단 주 
파수이다.

$$
H(s)=\frac{w_{c}}{s+w_{c}}
$$

속도에 필터를 적용하여 식(8)과 같이 나타낼 수 있으며, $\widehat{\Omega_{m}}(s)$ 는 식 $(2)$ 에서의 기계 각속도를 주파수 영역에서 나타 낸 것이며, $\widetilde{\Omega_{m}}(s)$ 는 필터를 적용한 속도를 나타낸다.

$$
\widetilde{\Omega_{m}}(s)=H(s) \widehat{\Omega_{m}}(s)
$$

식 (8)을 Backward Euler Method를 이용하여 식 (9)와 같이 나타낼 수 있으며, $T_{s}$ 는 샘플링 주기이다.

$$
\widetilde{\Omega_{m}}[n]=\frac{w_{c} T_{s}}{1+w_{c} T_{s}} \Omega_{m}[n]+\frac{1}{1+w_{c} T_{s}} \widehat{\Omega_{m}}[n-1]
$$

주파수 분석을 통해 속도 변화에 의한 노이즈 성분이 나 타나는 주파수가 구동 주파수 $f_{e}\left(=\frac{w_{e}}{2 \pi}\right)$ 의 배수임을 확인하 였는데, 속도 변화의 영향을 제거하기 위하여 $w_{c}<w_{e}$ 를 만 족하도록 차단 주파수를 결정해야한다. 하지만 차단 주파수 를 너무 작게 설정하면 느린 응답 속도로 인하여 전동기의 가감속 시 $\mathrm{ZCP}$ 를 추정 할 수 없는 문제가 발생한다. 따라서 차단 주파수를 설정 할 때 전동기의 기계적 시정수 $\tau_{m}$ 를 고 려하여 설정해야 하며, 필터를 적용하는 최저 속도의 차단주 파수 $w_{c(\min )}$ 를 기계각속도의 약 두 배 이상으로 식(10)과 같 이 제한하기로 한다.

$$
w_{c(\min )}>\frac{2}{\tau_{m}}(2 \pi)
$$

식(10)를 만족하며 전 속도 영역에서 노이즈의 영향을 제 거할 수 있도록 차단 주파수를 식 (11)과 같이 설정하였다.

$$
w_{c}=\frac{1}{2} w_{e}
$$

본 논문에서 $500[\mathrm{rpm}]$ 이상의 속도 범위에서 필터를 적용 시키므로 $w_{c(\min )}$ 는 식 (12)와 같고, 실험에 사용한 전동기의 기계적 시정수가 식 (13)와 같으므로 식 (10), (14)를 만족한다.

$$
\begin{aligned}
& w_{c(\text { min })}=\frac{1}{2}(500) \frac{2 \pi}{60} \frac{P}{2}=157[\mathrm{rad} / \mathrm{s}] \\
& \tau_{m}=\frac{J}{B}=\frac{0.005 m}{0.11 \mathrm{~m}}=0.45[\mathrm{sec}] \\
& w_{c(\text { min })}>\frac{2}{(0.5)}(2 \pi) \approx 25[\mathrm{rad} / \mathrm{s}]
\end{aligned}
$$

식(9)의 주파수 영역에서의 필터링 된 속도를 라플라스 역변환을 이용하여 시간 영역으로 표현한 것을 $\widetilde{w_{m}}$ 이라 할
때, 식 (15)과 같이 ZCP간의 주기를 계산 할 수 있다.

$$
\widetilde{T_{z c}}=\frac{60}{\widetilde{w_{z c}}(P / 2)} \frac{1}{6}
$$

\section{3 실험 및 검증}

실험을 통해 설계한 필터를 적용함으로써 $\mathrm{ZCP}$ 추정 오차 가 저감됨을 확인하였다. 실험 및 검증을 위하여 그림 8과 같이 $\mathrm{BLDC}$ 센서리스 구동 시스템을 구성하였다. BLDC 센 서리스 구동 시스템에는 $\mathrm{ZCP}$ 추정을 위한 단자 전압과 직 류 링크 전압 측정부가 있으며, $\mathrm{ADC}$ 모듈을 통해 각 전압 이 샘플링된다. 샘플링된 전압들을 이용하여 $\mathrm{ZCP}$ 를 검출하 여 $\mathrm{ZCP}$ 간의 주기를 계산한다. 설계된 프로그래머블 저역 통 과 필터를 적용하여 $\mathrm{ZCP}$ 간의 주기로부터 속도를 계산하여 전류의 전환 시점을 계산하고 전환 순서를 결정한다. 계산 된 속도와 지령 속도로부터 PI 속도 제어기를 통해 PWM 방식을 사용하기 위한 인가전압이 결정된다. PWM 모듈에 서는 전환 순서와 인가전압을 이용하여 전력 변환부인 3상 인버터에 $\mathrm{PWM}$ 을 출력한다. 실험에 사용한 전동기의 파라 미터는 Table. 1 과 같고, $\mathrm{PWM}$ 스위칭 주파수는 $10[\mathrm{kHz}]$ 로 설정하였다.

$\mathrm{ZCP}$ 추정 오차가 미치는 영향에 대하여 분석하기 위하여 $500,1500,2500[\mathrm{rpm}]$ 으로 구동 할 때 필터를 적용하지 않은 경우, 필터를 적용한 경우에 대하여 각 각을 Method 1 과 Method 2라 하고, 3상 전류의 리플률( $\mathrm{RF}$, Ripple Factor)을 비교하였다. 전류의 리플률은 2 상 도통 구간 내에서 발생하 는 피크 전류의 최대값 $i_{\max 1}$ 과 최소값 $i_{\max 2}$ 으로 식 (16)과 같이 구하였다.

$$
R F=\frac{i_{\max 1}-i_{\max 2}}{i_{\max 1}} \times 100[\%]
$$

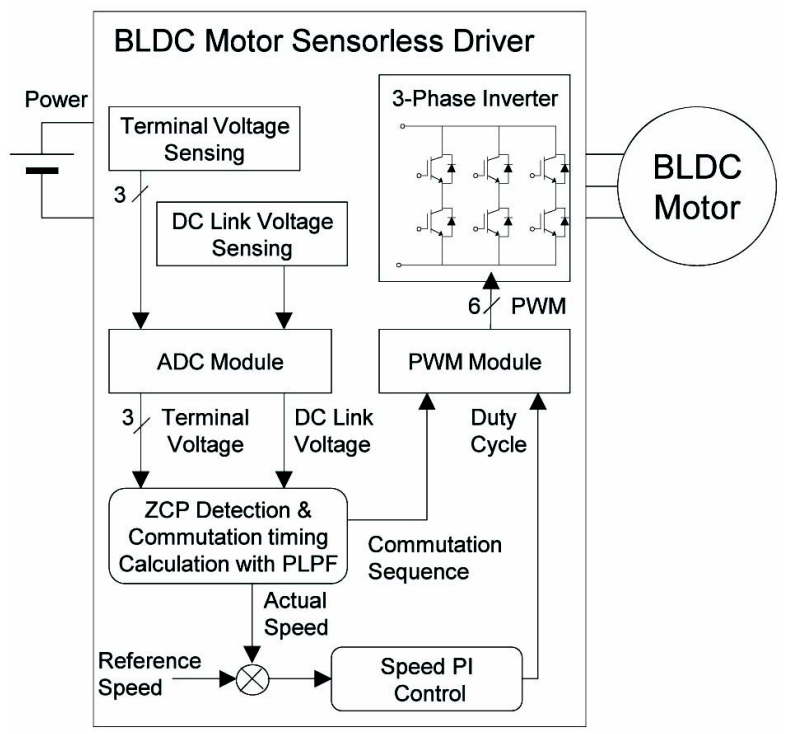

그림 $8 \mathrm{BLDC}$ 전동기 센서리스 구동 시스템

Fig. 8 BLDC motor sensorless drive system 
표 1 BLDC 전동기 파라미터

Table 1 Parameters of BLDC motor

\begin{tabular}{||l||c|c||}
\hline \hline Parameter & Value & Unit \\
\hline \hline DC bus voltage & 24 & $\mathrm{~V}$ \\
\hline Phase resistance & 0.158 & $\Omega$ \\
\hline Phase inductance & 0.176 & $\mathrm{mH}$ \\
\hline Back-EMF constant & 6.55 & $\mathrm{mV} /(\mathrm{rad} / \mathrm{s})$ \\
\hline Rated speed & 3000 & $\mathrm{rpm}$ \\
\hline Number of pole & 12 & - \\
\hline
\end{tabular}

$2500[\mathrm{rpm}]$ 으로 구동 시 3상 전류 파형을 각 각의 경우에 대하여 그림 9,10 에 나타냈으며, 구동 속도에 따른 전류 리 플률을 비교한 결과를 Table. 2에 정리하였다.

Method 1 의 경우, $\mathrm{ZCP}$ 추정 오차로 인해 $\mathrm{ZCP}$ 간의 주기 가 일정하지 않다. 따라서 실제 전류의 전환 이루어져야하 는 시점 보다 빠르거나 느린 시점에서 전류의 전환이 이루 어져 전류의 리플률이 크게 나타난다.

반면, 필터를 적용한 Method 2의 경우 $\mathrm{ZCP}$ 의 추정 오차 의 저감으로 인한 전류 리플이 감소하며, 500, 1500, $2500[\mathrm{rpm}]$ 에서 각 각 $24.0,5.8,16.9[\%]$ 감소하였다.

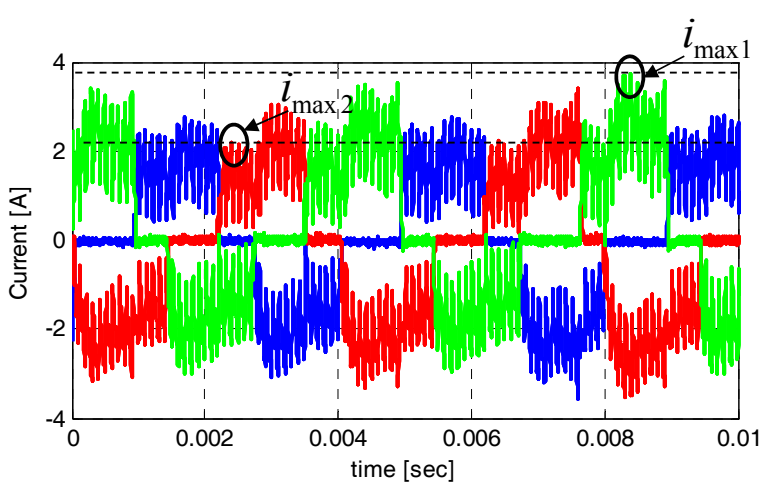

그림 9 2500[rpm] 구동 시 필터를 적용하지 않은 경우 3상 전류 파형 (Method 1)

Fig. 9 3-phase current wave without filter at 2500[rpm] (Method 1)

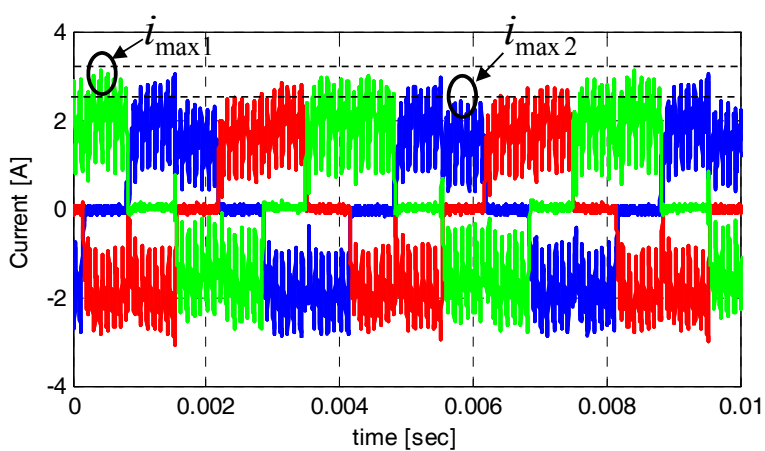

그림 10 2500[rpm] 구동 시 필터를 적용한 경우 3상 전류 파형 (Method 2)

Fig. 10 3-phase current wave with filter at 2500[rpm] (Method 2)
표 2 전류의 리플률

Table 2 Ripple factor of current

\begin{tabular}{|c||c|c||}
\hline Speed [rpm] & Method 1 [\%] & Method 2 [\%] \\
\hline \hline 500 & 50.3 & 26.3 \\
\hline 1500 & 24.2 & 18.4 \\
\hline 2500 & 39.3 & 22.4 \\
\hline
\end{tabular}

4. 결 론

이 논문은 $\mathrm{BLDC}$ 전동기의 센서리스 구동 시 속도에 따 라 차단 주파수가 가변되는 프로그래머블 저역 통과 필터를 속도에 적용하여, 단자 전압의 노이즈로 인한 $\mathrm{ZCP}$ 추정 오 차가 저감됨을 보였다. 필터를 설계하기 위해 $\mathrm{ZCP}$ 주기로 계산되는 속도를 주파수 영역에서 분석하였고, 구동 속도를 기본 주파수로하는 고조파에서 $\mathrm{ZCP}$ 추정 오차가 나타남을 보였다. 이를 바탕으로 속도에 따라 필터의 차단 주파수가 가변되는 프로그래머블 저역 통과 필터를 설계하였고, 실험 결과로부터 제안한 필터를 적용함으로써, 500, 1500, 2500 [rpm]의 속도에서 각 각 전류 리플률이 24.0, 5.8, 16.9[\%] 감소함을 보였다. $\mathrm{BLDC}$ 전동기 구동에서 전류 리플은 진 동, 소음의 원인이 되는 토크 리플을 증가시키는 가장 큰 요 인이므로, 제안한 필터를 적용함으로써 $\mathrm{BLDC}$ 전동기의 센 서리스 구동 시 성능 향상을 기대할 수 있다.

\section{감사의 글}

이 논문은 2013-2014년도 창원대학교 연구비에 의 하여 연구되었음

\section{References}

[1] Q. Tran, T. Chun, H. Lee, H. Kim and E. Nho, "Control Techniques of Sensorless BLDC Motor Drive for a Vehicle Fuel Pump Application," Transactions of KIEE, Vol.60, No.10, pp.1858- 1864, 2011.

[2] H. Kim, J. Bae, J. Jang and I. Joo, "The Characteristic Improvement of the Motor for Electric Compressor by the Lead Angle Control," KSAE Spring Conference Proceedings, pp.879- 882, 2012.

[3] S. Kim, S. Jeong, S. Rhyu and B. Kwon, "Reduction of Cogging Torque of BLDC Motor by Sinusoidal Air-Gap Flux Density Distribution," Transactions of KIEE, Vol.56, No.1, pp.57-65, 2007.

[4] H. Kim, H, Oh, J. Kim and C. Kim "A Study On the Phase Advance Angle of High Speed Operation for 7 Phase BLDC Motor Drives," Transactions of KIEE, Vol.56, No.11, pp.1930-1936, 2007.

[5] J. C. Moreira, "Indirect Sensing for Rotor Flux Position of Permanent Magnet AC Motors Operating Over a Wide Speed Range," IEEE Trans. Ind. Appl., 
vol. 32, no. 6, pp.1392-1401, Nov./Dec. 1996.

[6] S. Ogasawara and H. Akagi, "An approach to position sensorless drive for brushless dc motors," IEEE Trans. Ind. Applicat., vol.27, pp.928-933, Sept./Oct. 1991.

[7] G. Su and J. Mckeever, "Low cost sensorless control of brushless DC motors with improved speed range," IEEE Applied Power Electronics Conference, pp.286-292, 2002.

[8] D. song, S. Lee, T. Jung, S. Cho, S. Park and D. Kim, "Developement of Back-emf Filter Circuit for Driving Sensorless BLDC Motors," Transactions of KIPE, Vol.13, No.1, pp.63-69, 2008.

[9] R. Carlson, M. Lajoie-Mazenc and J. C. dos Fagundes, "Analysis of torque ripple due to phase commutation in brushless DC machines," IEEE Trans. Ind. Applicat., vol. 28, no. 3, pp.632-638, 1992

[10] E. Seo, K. Lee and W. Lee, "The effects of back-EMF signal noise and sampling period for BLDC motor sensorless drives at high speed," KSAE Spring Conference Proceedings, pp.1065-1068, 2013

[11] H. Yeo, T. Kim, J. Park, K. Lee and J. Yoo, "Performance Enhancement of a Sensorless Drive for Brushless DC Motors using Digital Filter," Transactions of KIEE, Vol.48B, No. 2, pp.63-68, 1999.

\section{저 자 소 개}

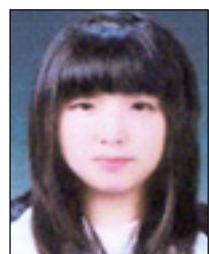

서 은 정 (徐 銀 正)

1989년 2월 5일 생, 2011년 창원 대학교 제어계측공학과 졸업, 2013년 동 대학원 제어계측공학과 졸업(석사)

E-mail : ejseo1989@gmail.com

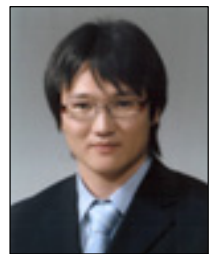

\section{이 강 석 (李 康 碩)}

1982년 4월 30일 생, 2008년 창원대학교 제어계측공학과 졸업, 2011년 동 대학원 제어계측공학과 졸업(석사), 현재 창원대 학교 제어계측공학과 박사과정 대학원생.

E-mail : ks1549@gmail.com

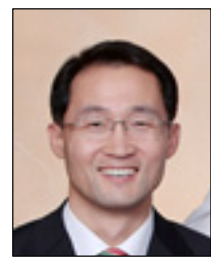

\section{이 우 택 (李 患 澤)}

1970년 11월 17일 생, 1996년 한양대학교 전기공학과 졸업, 1998 년 동 대학원 전기 공학과 졸업(석사), 2002년 동 대학원 자 동차공학과 졸업(박사), 현재 창원대학교 제어계측공학과 교수.

Tel : 055-262-7558

E-mail : wootaik@changwon.ac.kr 